bttp:/ / dx.doi.org/10.21707/gs.v11.n02a03

\title{
O USO DE VÍDEO DE CARÁTER REGIONAL COMO INSTRUMENTO DIDÁTICO PARA A EDUCAÇÃO AMBIENTAL
}

\author{
Francisca Araujo Costa Guedes ${ }^{1 *}$, Rodrigo Arantes Reis², Emerson \\ JoUCOSKI $^{3}$
}

'Mestre em Desenvolvimento Territorial Sustentável, Universidade Federal do Paraná - Setor Litoral.
Doutor em Ciências (Bioquímica), Universidade Federal do Paraná, Setor Litoral.
${ }^{3}$ Doutor em Ensino de Ciências - Universidade Federal do Paraná - Setor Litoral.
* Autor para correspondência: franciscaguedes@gmail.com

Recebido em 05 de julho de 2016. Aceito em 18 de março de 2017. Publicado em 29 de julho de 2017.

Resumo - A grave crise socioambiental mundial impõe a necessidade de busca de um novo modelo de civilização e de sociedade pautado numa nova ética da relação entre os seres humanos e a natureza. Repensar essa no âmbito escolar requer uma problematização do tema que deve ser contextualizado de forma significativa aos estudantes. Nesse sentido, a utilização de vídeos em sala de aula como estratégia de trabalho pode ser um recurso vantajoso para a prática pedagógica. O presente estudo apresenta a Educação Ambiental como uma dimensão da educação fundamental, utilizando o vídeo como estratégia de sensibilização e formação da consciência crítica acerca da problemática socioambiental de estudantes da Educação Básica, visando a instrumentalização para uma ação política e social transformadora. Trata-se de uma investigação qualitativa/quantitativa que usou a análise textual discursiva sobre o material produzido com o uso de diferentes meios didáticos. Foi realizada em cinco escolas, sendo quatro situadas no litoral do Paraná com o intuito de investigar a contribuição do uso do vídeo como recurso didático para a contextualização de determinados conceitos/conteúdos no processo de aprendizagem. Os resultados mostram a eficácia do uso do vídeo, em especial como a argumentação científica e a realidade potencializam a construção das ideias dos estudantes, pois os argumentos são justificados cientificamente e corroborados pela realidade. Além disso, percebeu-se como a curiosidade dos estudantes serve como ponto de partida para a realização de pesquisas sobre os problemas socioambientais no entorno, visando à instrumentalização para uma ação política e emancipatória dos educandos.

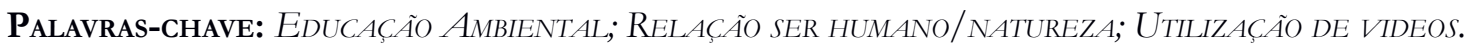

The USE OF REgIONAL VIDEO AS A TEACHING INSTRUMENT FOR AN ENVIRONMENTAL EDUCATION

Abstract - The socio-environmental global crisis imposes the need of searching a new model of civilization and society guided by a new ethical relationship between humans and nature. Rethinking this in a scholar scope requires a problematization that needs a contextualizationto students, in a significant way. In this sense, the use of video in classroom as a work strategy can be a useful resource for the pedagogical practice. This study presents environmental education as a dimension of basic education, using the video as anawareness strategy and a critical conscience shapingon the socio-environmental structural problems of basic education students, aiming to provide the instruments for a sociopolitical action transformation. This is a qualitative/quantitative research that used the discursive textual analysis on the material produced with the use of different teaching methods. It was performed in five schools, four located on the coast of Paraná in order to investigate the contribution of the video use as a teaching resource for contextualization of certain concepts/contents in the learning process. The results show the effectiveness of the video use, especially how the scientific questioning and the reality empowers the construction of the ideas of the students, for the arguments are 
justified scientifically and supported by reality. Besides, it was perceivedthatthe students' curiosity serves as a starting point for conducting researches onsurrounding socio-environmental issues aiming at providing instruments for an emancipatory and political action of the students.

KeYwords: ENVIRONMENTAL EdUCATION; RESPECT HUMAN/ NATURE; USE OF VIDEOS.

\section{El uSO DE VIDEO DE CARÁCTER REGIONAL COMO INSTRUMENTO DIDÁCTICO PARA LA EDUCACIÓN AMBIENTAL}

RESumen - La grave crisis socioambiental global impone la necesidad de buscar un nuevo modelo de civilización y de sociedad pautado por una nueva ética de la relación entre los seres humanos y la naturaleza. Repensar esta en el ámbito escolar requiere una problematización del tema que debe ser contextualizada de manera significativa para los estudiantes. En este sentido, el uso del video en el aula como estrategia de trabajo puede ser un recurso ventajoso para la práctica pedagógica. Este estudio presenta la educación ambiental como una dimensión de la educación básica, utilizando el video como estrategia de sensibilización y formación de la conciencia crítica acerca de la problemática socioambiental de los estudiantes de educación básica, buscando la instrumentalización para una acción política y social transformadora. Se trata de una investigación cualitativa/cuantitativa que utilizó el análisis textual discursivo sobre el material producido con el uso de diferentes medios didácticos. Se llevó a cabo en cinco escuelas, de las cuales cuatro estaban situadas en la costa del Paraná con el fin de investigar la contribución del uso del video como recurso didáctico para la contextualización de determinados conceptos / contenidos en el proceso de aprendizaje. Los resultados muestran la eficacia de la utilización de vídeo, especialmente considerando como la argumentación científica y la realidad potencian la construcción de las ideas de los estudiantes, pues los argumentos están justificados científicamente y corroborados por la realidad. Además, se percibió como la curiosidad de los estudiantes sirve como punto de partida para la realización de investigaciones sobre los problemas socioambientales en el entorno, buscando la instrumentalización para una acción política y emancipadora de los estudiantes.

Palabras-clave: Educación Ambiental; Relación ser humano/naturaleza; El uso de Videos.

\section{INTRODUÇÃO}

De acordo com o Atlas Brasileiro de Desastres Naturais 1991 a 2010 (Atlas, 2012), os desastres naturais mais frequentes no Brasil nos últimos vinte anos são as estiagens e secas, seguidos de inundações bruscas, alagamentos e inundações graduais, vendavais, ciclones e os granizos. A preocupação com as mudanças climáticas advindas das ações humanas tem levado diversos cientistas a estudos sobre o clima e estudos recentes indicam um aquecimento de $4^{\circ} \mathrm{C}$ a $7^{\circ} \mathrm{C}$ nos próximos cem anos, o que causaria o colapso da civilização. De acordo com a avaliação de um grupo reunido com o intuito de avaliar os riscos de mudanças climáticas extremas, embora a probabilidade de que o aquecimento da Terra ultrapasse os $4{ }^{\circ} \mathrm{C}$ seja baixa, as potenciais consequências são tão alarmantes que se faz necessário que sejam consideradas na formulação de políticas públicas decisões sobre o corte de emissão de gases de efeito estufa (Angelo, 2015).

A conduta humana moderna em relação à natureza tem influência sobre o agravamento das mudanças climáticas e dos desastres supostamente naturais. Na maioria dessas ocorrências há uma grande participação humana, seja pela sua atuação ou por sua omissão e, pela ausência de políticas públicas, a maioria dos desastres deixa de ser natural (Carvalho e Damacena, 2012). Os desastres ambientais têm sido cada vez mais recorrentes no Brasil e no mundo e são destaques nas agendas políticas das nações. Lima e Maluf (2011) afirmam que o tratamento internacional das questões climáticas e suas implicações no âmbito nacional foram determinantes 
para sua inserção na agenda e na formulação de políticas públicas no Brasil sobre as mudanças climáticas.

Nobre (2012) afirma que o modelo de desenvolvimento socioeconômico tradicional sempre teve como foco aumentar a elevação da qualidade de vida e alcançar um desenvolvimento social, contando com recursos naturais inesgotáveis e sem pensar nas externalidades ambientais deste modelo de crescimento econômico. O desafio hoje é alcançar o desenvolvimento sem comprometer a sustentabilidade ambiental do planeta, o que implica em mudança de comportamento de consumo, pois os recursos naturais são finitos. Segundo Furtado (1974), a base do sistema capitalista é o processo de acumulação e a elevação do nível de consumo das populações, causando efeitos diretos ou indiretos sobre os recursos naturais, sobretudo os recursos naturais não renováveis. O capitalismo criou um estilo de vida, privilégio de uma minoria, com alto impacto de depredação do mundo físico e tentar generalizá-lo seria um risco à sobrevivência da espécie humana, pois levaria ao colapso de toda uma civilização. A homogeneização imposta pelo sistema capitalista e o seu consequente processo de globalização tornam inviável a ideia de um crescimento econômico universal, pois o atual modelo de economia além de destruir o meio ambiente em larga escala, cria a ilusão de que o crescimento da economia gera desenvolvimento. Somente um projeto social voltado para a melhoria das condições de vida da população poderia transformar o crescimento econômico em desenvolvimento.

A Educação Ambiental, entendida como um processo de permanente aprendizagem que valoriza as diversas formas de conhecimento, deve sobretudo situar-se num contexto de formação da cidadania crítica, com consciência local e planetária (Jacobi, 2003), de formação de uma identidade e pertencimento a uma coletividade, o que requer uma nova forma de considerar a relação do homem com a natureza, a partir de uma nova ética, que implica outros valores morais e um novo jeito de ver o mundo e os homens. O objeto da Educação Ambiental é fundamentalmente a relação da sociedade humana com o meio ambiente e há uma lacuna nessa relação que é necessária eliminar, para isso é indispensável se reconstruir o sentimento de pertencimento à natureza, ao fluxo de vida do qual se participa e "tomar consciência de que os problemas ambientais estão essencialmente associados a questões socioambientais ligadas a jogos de interesse e de poder, e a escolhas de valores" (Sauvé, 2005).

A relação ser humano/natureza precisa ser revista nos âmbitos socioambientais, políticos, econômicos, culturais e o papel da educação formal nesse sentido é fundamental, desde a Educação Infantil até a de nível Superior. A Educação Ambiental é uma dimensão essencial da educação fundamental, pois em sua práxis educativa e social objetiva a construção de valores, conceitos, habilidades e atitudes que possibilitam o entendimento da realidade de vida e a atuação consciente e responsável de atores sociais, individuais e coletivos no ambiente. Sua práxis contribui para a busca de um novo modelo de civilização e de sociedade pautado numa nova ética da relação entre os seres humanos e a natureza, pois possibilita o desenvolvimento de uma ampla consciência crítica das relações sociais e de produção que situam a inserção humana na natureza (Loureiro, 2005).

A formação voltada à cidadania crítica pressupõe o desenvolvimento de sujeitos que se percebam historicamente, socialmente e culturalmente, comprometidos com o meio em que vivem. Porém, o senso comum ainda é a base para a prática pedagógica de muitos educadores, sendo necessária sua superação e construção de uma prática educativa dialética que leve à formação da cidadania crítica e à emancipação dos educandos. A escola deve se transformar em um ambiente em que os envolvidos tenham a possibilidade de perceberem a natureza em um contexto de práticas sociais imbricadas, com o cuidado de se evitar ações localizadas e distantes da realidade social. Estabelece-se a obrigatoriedade da Educação Ambiental como "componente essencial e 
permanente da educação nacional, devendo estar presente, de forma articulada, em todos os níveis e modalidades do processo educativo, em caráter formal e não-formal" (Brasil, 1999, Art.2 $2^{\circ}$. Jacobi (2003) destaca que a Educação Ambiental no Brasil até agora trata de temas como o lixo, a proteção do verde, uso e degradação de mananciais e a conscientização das pessoas em relação à poluição do ar, sendo que as responsabilidades ainda são relegadas aos órgãos governamentais e aceitas passivamente pela população. Loureiro (2009) aponta que a Educação Ambiental deve ser emancipatória, ou seja, elemento de transformação social, pautadas no diálogo, no exercício da cidadania, no empoderamento dos sujeitos, na compreensão do mundo em sua complexidade e da vida em sua totalidade. Uma prática como práxis social que contribua para um processo de construção de uma sociedade pautada nos princípios de sustentabilidade da vida, na atuação política consciente e firmada numa nova ética ecológica.

Repensar a relação ser humano/natureza no âmbito escolar requer uma problematização do tema que deve ser contextualizado de forma significativa para o estudante. Nesse sentido, a utilização de vídeos em sala de aula como instrumento de trabalho com a linguagem audiovisual pode ser um recurso vantajoso para o trabalho pedagógico. A relevância do vídeo segundo Moran (1995) está no fato de este ser sensorial, visual e percebido através das linguagens falada, musical e escrita que interagem entre si de forma interligada e superpostas. É um instrumento que combina a comunicação sensorial sinestésica com a audiovisual, a intuição com a lógica, a emoção com a razão começando pelo sensorial, pelo emocional e pelo intuitivo para atingir posteriormente o racional. Quanto mais próximo da realidade do estudante, tanto mais efetivo o vídeo pode ser para a percepção dos problemas em seu entorno e, de acordo com Arroyo, é uma forma de contextualizar o conhecimento e torná-lo mais instigante, pois traz "as vivências dos educandos e educadores e suas experiências sociais como objeto de pesquisa, de atenção, de análise e de indagação" (Arroyo, 2013). A sala de aula deve ser o ponto de partida que leve professores e estudantes ao questionamento e a pesquisa da realidade em seu entorno e, se necessário, para nela intervir (Demo, 2011).

Nosso estudo foca na proposta do uso de recursos audiovisuais de caráter regional, como instrumento didático para investigar a formação e a construção de uma conscientização crítica de estudantes da Educação Básica acerca da problemática ambiental e do desenvolvimento local/regional. Foi selecionado o documentário "Quem acordou o Dragão?", produzido pelo programa de extensão "Laboratório Móvel de Educação Científica" da UFPR (Labmóvel, 2012), que narra o processo de transformação decorrentes das chuvas e deslizamentos de 11 de março de 2011 que ocorreram nos municípios de Antonina, Guaratuba, Morretes e Paranaguá na região litorânea do Estado do Paraná; também se retratam as dificuldades e a precária situação política local; apresentase a explicação científica do fenômeno; discutem-se as problemáticas ambientais recentes como a alteração do Código Florestal; e, sob a metáfora do dragão, lança indagações sobre uma nova forma de se relacionar com a natureza que a humanidade necessita adquirir. Verificou-se se o fato dos estudantes terem vivenciado ou não os acontecimentos apresentados no vídeo documentário apresentariam diferenças entre as escolas. Assim sendo, o documentário serviu ao propósito de apresentar explicações mais elaboradas, isto é, científicas do fenômeno ocorrido em março de 2011, além de discutir problemáticas ambientais e provocar os sujeitos sobre a necessidade de uma nova forma de se relacionar com a natureza.

\section{Material e mÉtodos}


Trata-se de um estudo qualitativo pela metodologia de Estudo de Caso para a coleta de dados, envolvendo 113 estudantes que participaram da mesma atividade aplicada em cinco escolas selecionadas para a pesquisa: Colégio Estadual Professora Tereza da Silva Ramos, em Matinhos; Colégio Estadual Rocha Pombo, em Morretes; Escola Estadual Professora Maria Arminda, em Antonina; Colégio Estadual Leôncio Correia, em Curitiba; e Colégio Estadual Cubatão, na região rural do município de Guaratuba. O estudo foi dividido em dois momentos: primeiro se realizou a análise das charges sobre a temática "desastres ambientais e a relação seres humanos e natureza", seguida de produção textual e socialização das ideias que emergiram; num segundo momento apresentou-se o documentário “Quem Acordou o Dragão?”, para depois se realizar um debate sobre o vídeo e a reescrita do texto da atividade anterior.

Pesquisaram-se cinco turmas de nono ano do Ensino Fundamental II, sendo quatro em escolas situadas nos municípios de Antonina, Guaratuba, Matinhos e Morretes, no litoral do Paraná e uma na capital Curitiba. As escolas foram escolhidas considerando sua localização em relação ao desastre ambiental de 2011 retratados no documentário. Os municípios de Antonina, Guaratuba e Morretes foram diretamente afetados pelo desastre, mas Matinhos e Curitiba não foram diretamente afetados, porém tiveram efeitos secundários, uma vez que as rodovias de acesso que ligam Curitiba ao Litoral do Estado foram interditadas pela queda de barreiras e destruição de pontes. O estudo teve a autorização dos gestores das escolas e os responsáveis pelos estudantes assinaram um Termo de Consentimento Livre e Esclarecido. As atividades foram desenvolvidas no período de abril a julho de 2015, sendo utilizadas quatro horas/aula em cada turma. Antes das atividades os estudantes responderam a um questionário informando alguns dados gerais, sociais e ambientais. A partir do questionário obteve-se um perfil de cada turma/escola.

Foram definidas duas dimensões de análise a priori: "Percepção Ambiental e da Relação Ser Humana/ Natureza dos Estudantes antes da Apresentação do Vídeo"; e "Mudanças de Concepção dos Estudantes sobre a Questão Ambiental e a Relação Ser Humano/Natureza após a Apresentação do Vídeo”. Os resultados das produções textuais e das transcrições dos diálogos filmados, na socialização de ideias e debates, foram codificados utilizando a técnica da Análise Textual Discursiva (Moraes e Galiazzi, 2006). Os textos produzidos pelos alunos foram transcritos ao todo ou em partes significativas, as gravações em vídeo foram transcritas e em seguida utilizou-se do pacote RQDA no processo de unitarização para a criação das unidades de significado e das categorias empíricas. Nesse processo diferentes unidades de significados, mas com ideias em comum, foram atribuídos a uma categoria: por exemplo, a categoria "questão do lixo" foi atribuída aos trechos em que o estudante cita o problema do lixo como causa das enchentes/alagamentos. As unidades de significado também podem pertencer a outras categorias, pois podem ser vistas sob diferentes pontos de vista. A posteriori as categorias passaram por uma análise quantitativa calculando-se a frequência de uma em relação ao total. Essas foram classificadas em categorias mais abrangentes e agrupadas sob as dimensões de análise.

Momento 1: Análise de Charges

A primeira atividade proposta aos alunos foi a reflexão de charges sobre os "Desastres Ambientais e a relação Ser Humano/Natureza" que consistia no levantamento do seus conhecimentos prévios sobre a temática para instigar a sua curiosidade pelo tema proposto. O objetivo foi obter a percepção inicial do aluno sobre a questão ambiental e sobre a relação ser humano e natureza. Foram apresentadas três charges críticas sobre os 
fenômenos estudados: a primeira mostrando o problema de enchentes, a segunda o contraste entre a seca e as enchentes que ocorreram simultaneamente em dois estados brasileiros (seca em Santa Catarina e enchentes no Espírito Santo) e na terceira o risco de desabamentos ressaltando a questão da negligência, omissão, falta de preservação, corrupção e o descaso. A partir delas os alunos foram convidados a refletir sobre o tema e a expressar suas impressões. Após isso, os estudantes socializaram suas ideias e, sem seguida, produziram os textos.

\section{Momento 2: Apresentação de Video Documentário}

Nesse momento os alunos assistiram ao documentário, seguido de uma chuva de ideias. Buscou-se observar possíveis mudanças de percepção ou aprofundamento das ideias preconcebidas sobre a temática em questão. Nessa fase do processo de ensino-aprendizagem ocorre a instrumentalização, que consiste em dar subsídios ao educando para a construção de novos conceitos ou apropriação de conhecimentos elaborados, historicamente construídos. Nela o professor faz a mediação entre o aluno e o objeto do conhecimento, entre o que ele anteriormente conhecia de forma empírica e o conhecimento mais elaborado, aqui subentendido como o conhecimento científico. Partindo do saber cotidiano do aluno o professor utiliza instrumentos didáticopedagógicos para mediar a apropriação do conhecimento elaborado para uma melhor aprendizagem. Após a apresentação do documentário e discussões sobre seu conteúdo, os estudantes foram convidados a reescreverem o texto elaborado no primeiro momento.

\section{Resultados E Discussão}

\section{Perfil das Escolas a partir do Questionário}

- Colégio Estadual Professora Tereza da Silva Ramos (Matinhos-PR): situado em área não afetada diretamente pelo desastre de 2011, mas com histórico de alagamentos/enchentes - 54,5\% dos estudantes vivenciaram esse tipo de situação. Seu perfil socioeconômico é diverso com 13,6\% de beneficiários do Programa Bolsa Família; somente 3,3\% dos membros das famílias possuem escolaridade de nível superior e da turma $27,2 \%$ dos estudantes estão em defasagem ano/idade.

- Colégio Estadual Rocha Pombo (Morretes-PR): situado na área de influência, com 87,1\% dos estudantes que vivenciou desastres (74,2\% enchentes; $3,2 \%$ desmoronamentos; $9,7 \%$ outros), em especial o de 11 de março de 2011. Com situação socioeconômica diversa tem 19,4\% de beneficiários do Programa Bolsa Família; dos familiares 10,5\% possuem escolaridade de nível superior e 5,2\% a pós-graduação; da turma 16,1\% dos estudantes estão em defasagem ano/idade.

- Escola Estadual Professora Maria Arminda (Antonina-PR): situada em município diretamente afetado pelo desastre de 2011, porém em Bairro fora da área de influência, sendo que nenhum dos estudantes vivenciou diretamente a ocorrência. Contudo, 56,3\% vivenciaram outras situações: 43,8\% enchentes; 12,5\% outros. Seu perfil socioeconômico é considerado baixo: $100 \%$ possuem renda média familiar de até três salários mínimos e apenas 1,31\% dos familiares possui escolaridade de nível superior; 31,3\% são beneficiários do Programa Bolsa Família e da turma 62,5\% dos estudantes estão em defasagem 
ano/idade.

- Colégio Estadual Leôncio Correia (Curitiba-PR): situado em área fora de abrangência do desastre de 2011, com estudantes residentes em diversos bairros de três municípios distintos, dos quais 25,9\% vivenciou algum tipo de emergência civil: $14,8 \%$ enchentes; $3,7 \%$ desmoronamentos; 7,4\% outros. Sua situação socioeconômica é diversa com 7,4\% de beneficiários do Programa Bolsa Família; dos familiares 22,2\% possuem escolaridade de nível superior e 14,8\% pós-graduação e da turma 96,3\% dos estudantes estão em defasagem ano/idade.

- Colégio Estadual Cubatão (Guaratuba-PR): localizado em área rural totalmente afetada pelo desastre de 2011, sendo que 64,7\% vivenciou a ocorrência. Seu perfil socioeconômico é baixo com 29,4\% de beneficiários do Programa Bolsa Família; apenas 2,6\% dos familiares possuem escolaridade de nível superior e pós-graduação e da turma 23,5\% dos estudantes estão em defasagem ano/idade.

O perfil possibilitou perceber que o fato da escola ter vivenciado situações de emergência civil, sobretudo nos casos de enchentes, foi o fator que mais influenciou na participação e interesse dos alunos em relação às atividades desenvolvidas. O Colégio Estadual Rocha Pombo teve o maior índice $(87,1 \%$ ) e foi a turma que demonstrou maior interesse em pesquisar sobre os desastres ambientais. Contrapondo-se ao Colégio Estadual Leôncio Correia $(25,9 \%$ ) onde os alunos tiveram pouca experiência nesse sentido e foi a turma que teve a menor participação no debate sobre o documentário - poucos lembravam do desastre de 2011 - apesar disso, todos reescreveram o texto e deixaram suas impressões sobre o vídeo. As escolas Professora Maria Arminda (56,3\%), Cubatão (64,7\%) e Professora Tereza da Silva Ramos (54,5\%) também se envolveram mais nos momentos de socialização das ideias sobre as charges e no debate sobre o documentário do que os estudantes do Leôncio Correia. No caso do Colégio Tereza Ramos, apesar de não estar situado em área diretamente afetada pelo desastre de 2011, está próximo da ocorrência e a maioria dos estudantes conheciam o fato; o município do colégio possui mais históricos de experiências com enchentes/alagamentos do que o Leôncio Correia.

Os estudantes que vivenciaram o desastre de 2011 também demonstraram maior interesse em pesquisarem sobre o assunto: foi o caso dos alunos do Colégio Estadual Rocha Pombo que estavam se preparando para a Feira de Ciências e, apesar de já terem definido os temas de estudo (a problemática do lixo), demonstraram interesse em mudar seus projetos para apresentar a questão dos desastres ambientais à comunidade; corroborando a ideia de Arroyo (2013) de que as experiências sociais enriquecem o conhecimento e têm significado. Nos estabelecimentos Cubatão e Professora Maria Arminda os estudantes citaram, mesmo sem conhecer o tema, o desastre de 2011 antes mesmo da apresentação do vídeo e ao se depararem com imagens (charges) sobre a temática “desastres ambientais", imediatamente associaram-nas aos fatos ocorridos em 2011.

A Tabela 1 apresenta os percentuais das frequências (f \%) pelo total das frequências $\square \mathrm{f} \%$ ) de cada categoria antes e depois da apresentação do vídeo por escolas, sendo que nesses percentuais não foram contadas as categorias que apareceram nas entrevistas; horizontalmente aparecem as categorias de análise: Argumentos científicos e/ou da realidade; Senso comum da educação ambiental; Relação homem natureza; Educacional; Política e as categorias empíricas (em maio número). 


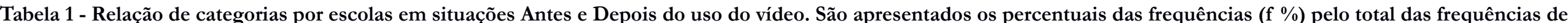

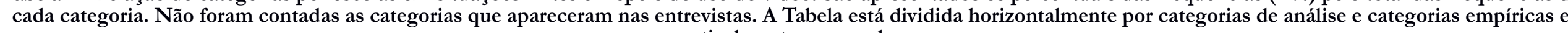
verticalmente por escolas.

\begin{tabular}{|c|c|c|c|c|c|c|c|c|c|c|c|}
\hline \multirow[b]{2}{*}{ Categoria de análise } & \multirow[b]{2}{*}{ Categorias } & \multicolumn{2}{|c|}{ Maria Arminda } & \multicolumn{2}{|c|}{ Cubatão } & \multicolumn{2}{|c|}{ Leôncio Correa } & \multicolumn{2}{|c|}{ Rocha Pombo } & \multicolumn{2}{|c|}{ Tereza Ramos } \\
\hline & & Antes & Depois & Antes & Depois & Antes & Depois & Antes & Depois & Antes & Depois \\
\hline \multirow{7}{*}{$\begin{array}{l}\text { Argumentos científicos } \\
\text { e/ou da realidade }\end{array}$} & $\begin{array}{l}\text { Argumentos e explicações } \\
\text { científicas sobre o desastre }\end{array}$ & - & $36,4 \%$ & - & $9,1 \%$ & - & $13,9 \%$ & - & $18,8 \%$ & - & $28,6 \%$ \\
\hline & Sobre o documentário & - & $9,1 \%$ & - & & - & $2,8 \%$ & - & $40,6 \%$ & - & $38,1 \%$ \\
\hline & Depoimentos sobre 2011 & $5,0 \%$ & $18,2 \%$ & $2,8 \%$ & $31,8 \%$ & - & - & - & - & - & - \\
\hline & Açõ̃es pós desastre 2011 & $15,0 \%$ & - & - & $4,5 \%$ & - & - & - & $3,1 \%$ & - & - \\
\hline & Linguagem visual & - & - & - & & - & $2,8 \%$ & - & - & - & - \\
\hline & Metáfora do Dragão & - & - & - & & - & $5,6 \%$ & - & - & - & - \\
\hline & \multicolumn{2}{|c|}{ Subtotal $=20,0 \%$} & $63,6 \%$ & $2,8 \%$ & $45,5 \%$ & & $25,0 \%$ & & $62,5 \%$ & & $66,7 \%$ \\
\hline \multirow{10}{*}{$\begin{array}{l}\text { Senso comum da } \\
\text { Educação Ambiental }\end{array}$} & Poluição & - & - & $2,8 \%$ & $4,5 \%$ & $9,1 \%$ & $13,9 \%$ & - & - & - & - \\
\hline & Mudanças climáticas & $5,0 \%$ & - & $5,6 \%$ & $4,5 \%$ & - & - & - & - & - & - \\
\hline & Desmatamento & - & - & $11,1 \%$ & $4,5 \%$ & - & - & - & - & - & - \\
\hline & Aumento da tecnologia & - & - & & - & - & - & - & $3,1 \%$ & - & - \\
\hline & Efeito estufa & $5,0 \%$ & - & & - & - & - & - & - & - & - \\
\hline & Preservação & - & - & $2,8 \%$ & $4,5 \%$ & $6,1 \%$ & $2,8 \%$ & $12,5 \%$ & - & $3,8 \%$ & - \\
\hline & Sensibilização & - & - & - & $4,5 \%$ & - & - & - & - & - & - \\
\hline & Prevenção & $10,0 \%$ & - & $8,3 \%$ & - & $3,0 \%$ & - & $12,5 \%$ & $3,1 \%$ & $3,8 \%$ & - \\
\hline & Aquecimento Global & - & - & $5,6 \%$ & - & - & - & - & - & - & - \\
\hline & Subtotal $=$ & $55,0 \%$ & $18,2 \%$ & $55,6 \%$ & $22,7 \%$ & $45,5 \%$ & $30,6 \%$ & $91,7 \%$ & $12,5 \%$ & $30,8 \%$ & $9,5 \%$ \\
\hline \multirow{3}{*}{ Relação homem x natureza } & Questão social & $5,0 \%$ & - & - & - & $6,1 \%$ & - & - & - & $3,8 \%$ & - \\
\hline & Aumento populacional & - & - & - & - & - & - & - & $3,1 \%$ & - & - \\
\hline & Subtotal $=$ & $10,0 \%$ & & $13,9 \%$ & $4,5 \%$ & $9,1 \%$ & $5,6 \%$ & $4,2 \%$ & $12,5 \%$ & $7,7 \%$ & $14,3 \%$ \\
\hline \multirow{6}{*}{ Educacional } & Conscientização & - & - & - & $4,5 \%$ & - & $2,8 \%$ & - & - & - & - \\
\hline & Educação ambiental & $5,0 \%$ & - & - & - & - & - & - & $3,1 \%$ & - & - \\
\hline & Falta de consciência & - & - & - & - & $15,2 \%$ & $8,3 \%$ & - & - & $7,7 \%$ & - \\
\hline & Falta de educação & - & $9,1 \%$ & - & - & - & - & - & - & $3,8 \%$ & - \\
\hline & Crítica ao ensino & $5,0 \%$ & - & - & - & - & - & - & - & - & - \\
\hline & Subtotal $=$ & $10,0 \%$ & $9,1 \%$ & & $4,5 \%$ & $15,2 \%$ & $11,1 \%$ & & $3,1 \%$ & $11,5 \%$ & \\
\hline \multirow{8}{*}{ Política } & Responsabilidades & $5,0 \%$ & $9,1 \%$ & $25,0 \%$ & $13,6 \%$ & $18,2 \%$ & $25,0 \%$ & $4,2 \%$ & $9,4 \%$ & $46,2 \%$ & $9,5 \%$ \\
\hline & Descaso & - & - & - & - & $6,1 \%$ & $2,8 \%$ & - & - & - & - \\
\hline & Falta de investimentos & - & - & - & $4,5 \%$ & - & - & - & - & $3,8 \%$ & - \\
\hline & Ganância & - & - & $2,8 \%$ & - & - & - & - & - & - & - \\
\hline & $\begin{array}{l}\text { Mau uso dos recursos } \\
\text { naturais }\end{array}$ & - & - & - & $4,5 \%$ & - & - & - & - & - & - \\
\hline & Omissão & - & - & - & - & $6,1 \%$ & - & - & - & - & - \\
\hline & Subtotal $=$ & $5,0 \%$ & $9,1 \%$ & $27,8 \%$ & $22,7 \%$ & $30,3 \%$ & $27,8 \%$ & $4,2 \%$ & $9,4 \%$ & $50,0 \%$ & $9,5 \%$ \\
\hline & \multicolumn{2}{|c|}{ Total geral $=100,0 \%$} & $100,0 \%$ & $100,0 \%$ & $100,0 \%$ & $100,0 \%$ & $100,0 \%$ & $100,0 \%$ & $100,0 \%$ & $100,0 \%$ & $100,0 \%$ \\
\hline
\end{tabular}


Percep̧cão Ambiental e da Relação Ser Humano/Natureza dos Estudantes antes da Apresentação do Vídeo

Ao se deparar com imagens dos desastres ambientais antes do vídeo, entre eles as enchentes, a seca e o risco de desmoronamento, as ideias que mais apareceram nos textos foram a Questão do lixo (média f \% na categoria $=34,3 \%$ ), a Prevenção (média f \% na categoria $=7,5 \%$ ), a Relação homem natureza (média f \% na categoria $=6,0 \%$ ) e as Responsabilidades (média f $\%$ na categoria $=19,7 \%$ ). Percebe-se que os estudantes fizeram uma relação direta entre as ações humanas - jogar lixo nas ruas - e o problema das enchentes. Além da problemática do lixo alguns alunos também relacionaram as ações humanas como causa dos desastres citando a falta de consciência das pessoas, o desmatamento, as queimadas, a falta de educação, a poluição, a falta de preservação ambiental, a destruição da camada de ozônio, o aquecimento global. Vários alunos também fizeram críticas às pessoas que constroem suas casas em áreas de risco, principalmente as construções em encostas com riscos de desmoronamentos; essa ideia apareceu nas cinco escolas pesquisadas na categoria Responsabilidades; no geral responsabilizaram os indivíduos sem considerar suas condições sociais e/ou econômicas. Além de tecer críticas também ao Governo por permitir essas construções ou não investir em construção de moradias adequadas a população de baixa renda, levando muitas vezes ao problema das invasões e criação de favelas.

Antes da apresentação do vídeo observa-se na maioria das escolas um maior número de categorias voltadas ao "Senso Comum da Educação Ambiental": das cinco escolas, quatro apresentam maior percentual nessa categoria de análise (>45\%), exceto a escola Tereza Ramos (30,8\%). Na categoria de análise "Política", a questão da responsabilidade está presente nas cinco escolas, com o percentual mais alto na Tereza Ramos (46,2\%). Na categoria de análise "Relação homem x natureza" a categoria "Relação homem natureza" aparece mais evidente antes do vídeo: pode se atribuir isso à temática da primeira atividade "Desastres Ambientais e a relação Ser Humano/Natureza" e se acredita que ao analisar as charges os estudantes tinham em mente essa relação.

Os estudantes demonstraram compreender a necessidade de uma tomada de consciência geral em torno das questões ambientais. Destacaram a responsabilidade dos órgãos governamentais e afirmaram que é necessário o investimento em infraestrutura e programas de prevenção: alguns alegaram que "o Governo só ajuda depois que o desastre acontece com ações paliativas e emergenciais, porém nada faz para solucionar as causas dos problemas"; no entanto, também perceberam que a responsabilidade não é só do Governo, mas a população como um todo também é responsabilizada por agir de forma inconsequente. Outros alegaram que é falta de consciência e que, apesar de saber dos riscos, as pessoas continuam agindo de forma prejudicial e sem responsabilidade. Poucos disseram que é falta de Educação, ou seja, subtendido aqui como a falta de conhecimento: nesse sentido, Leff (2010) afirma que a crise ambiental é fundamentalmente uma crise do conhecimento, o que exige das políticas ambientais uma política do conhecimento, isto é, o investimento em Educação Ambiental. No entanto, na concepção dos alunos, a Educação Ambiental não é algo trabalhado nos anos finais do Ensino Fundamental. Alegam que o cuidado com o meio ambiente só é ensinado nos anos iniciais, sobretudo na $2^{\mathrm{a}}$ série ou $3^{\circ}$ ano. Os alunos afirmaram que somente a disciplina de Ciências trabalha as questões ambientais, o que é contrário ao que se estabelece na Lei $n^{\circ} 9.795 / 1999$, Art. $2^{\circ}$, anteriormente citada. Também se percebeu nas falas dos estudantes, a ideia evidenciada por Jacobi (2003), de que a Educação Ambiental formal no Brasil seja feita de forma pontual com temas predominantes como o lixo, a proteção de matas e florestas, o problema da poluição e o uso e degradação de nascentes. Os alunos apresentaram ideias pouco críticas em relação aos problemas socioambientais, conforme se observa nas falas a seguir: 
Os problemas ambientais causam muitos desastres no nosso país, como enchentes, desmoronamentos, a seca ou uma tempestade. (...) Mas a culpa não é apenas da chuva, o homem pode não saber, mas ele também tem culpa de algumas coisas como as enchentes nas cidades maiores. Jogam muito lixo e não tem como a água escorrer. A seca sim pode ser culpa da chuva como no Nordeste. Já em caso de desmoronamento, para que fazer uma casa embaixo do morro? (Walter ${ }^{1}, 13$ anos, Colégio Estadual Cubatão).

As pessoas de hoje em dia não querem mais saber para onde vai o lixo e depois que chove e entope tudo os bueiros o povo coloca a culpa no governo que de certa forma é um pouco culpado por não usar o dinheiro dos impostos para arrumar a cidade e criar postos de reciclagem para que os lixos não fiquem sendo jogados na rua (Adriano, 14 anos, Colégio Estadual Professora Tereza da Silva Ramos).

O acúmulo de lixo no Brasil é grande e vai aumentando cada vez mais. E o pior é que tem pessoas que não fazem nada para ajudar, pelo contrário prejudicam ainda mais. Reciclar, reutilizar e reduzir não é difícil. Só que as pessoas deveriam tomar mais atitudes a esse respeito. Se as pessoas ajudassem nós poderíamos ter um mundo melhor (Thainá, 13 anos, Colégio Estadual Rocha Pombo).

$\mathrm{Na}$ fala dos estudantes o lixo apareceu como principal causa de enchentes/alagamentos e quando citaram os desmoronamentos as críticas principais foram em relação as pessoas que constroem casas em áreas de risco, sem uma percepção da questão socioeconômica envolvida nesse processo. A atribuição dos problemas exclusivamente à falta de consciência das pessoas demonstra uma visão que remete a uma prática de Educação Ambiental que enfatiza a dimensão ecológica da crise ambiental como se os problemas ambientais se originassem independentes das práticas sociais. Loureiro (2009) ressalta que os problemas ambientais devem ser pensados de forma articulada ao contexto social, cultural, histórico, político, ideológico e econômico. A Educação Ambiental deve ser emancipatória, ou seja, elemento de transformação social, pautadas no diálogo, no exercício da cidadania, no empoderamento dos sujeitos, na compreensão do mundo em sua complexidade e da vida em sua totalidade. Uma prática como práxis social que contribua para um processo de construção de uma sociedade pautada nos princípios de sustentabilidade da vida, na atuação política consciente e firmada numa nova ética ecológica.

Mudanças de Concepşão dos Estudantes sobre a Questão Ambiental e a Relação Ser Humano/Natureza após a Apresentação do Video

A primeira observação após o uso do vídeo foi a mudança em todas as frequências, anteriormente os pontos apresentados eram mais de senso comum e pontuais conforme defendido por Jacobi (2003). Percebeuse que em algumas escolas houve uma dispersão dos temas, com a mudança nas frequências ou nos temas abordados: na escola Maria Arminda foram usadas antes do vídeo 11 categorias e após apenas seis, na escola Cubatão aumentaram de 11 para 13 categorias usadas, na escola Leôncio Correa de 10 para 13 categorias, na Rocha Pombo de cinco para 10 categorias e na Tereza Ramos de nove para seis categorias.

Após assistirem ao vídeo os estudantes trouxeram à fala argumentos mais estruturados e usaram algumas das explicações científicas apresentadas no documentário ou depoimentos sobre a realidade vivenciada no desastre: a categoria "Argumentos e explicações científicas sobre o desastre" teve aumento em todas as escolas - antes nem mesmo havia sido percebida (frequências nulas no Tabela 1) e as outras categorias dentro da categoria de análise "Argumentos científicos e/ou da realidade" também sofreram aumentos consideráveis na média houve um aumento de 52,7\% nas frequências dessas categorias. De forma geral, após o vídeo as 1 Os nomes dos alunos são fictícios para resguardar a privacidade dos mesmos. 
alegações ganharam mais qualidade e diversidade e passaram a ser baseadas em dados mais fundamentados com os quais constroem suporte à conclusão. Outro ponto importante neste segundo momento são as muitas perguntas que surgem em três das cinco escolas pesquisadas. A partir disso pode se instigar o interesse pela pesquisa, tornar-se o ponto de partida para a problematização da realidade ao entorno podendo se fazer das vivências e experiências sociais, objeto de pesquisa, análise e indagação (Arroyo, 2013). Segundo Moran (1995), a linguagem audiovisual aguça a imaginação e reinveste a afetividade com um papel essencial de intervenção no mundo, desenvolvendo múltiplas atitudes perceptivas. Particularmente a metáfora do dragão apresentada no documentário suscitou questionamentos sobre as causas dos desastres ambientais. Imagens de um grande terremoto no Japão e da inundação e deslizamentos ocorridos no Litoral do Paraná em 11 de março de 2011, causando grandes destruições, são seguidas de uma narrativa que compara a força de destruição da natureza ao despertar de um dragão enfurecido. Os estudantes se sensibilizaram com a imagem do dragão desperto e da destruição por ele causada, tentaram responder ao questionamento "Quem acordou o dragão?" e buscaram explicações ao fenômeno ocorrido. Na fala de Fábio aparece a ideia de que é preciso investigar/pesquisar os fenômenos para evitá-los ou diminuir os prejuízos.

Segundo o vídeo nós despertamos o dragão que são os desastres ambientais. Isso foi despertado por consequência das nossas atitudes com o meio ambiente. Vários desastres como desabamentos poderiam ser amenizados se tivéssemos consciência do que fazemos e pensássemos nas consequências que nossas atitudes com a natureza trarão no dia de amanhã. Tais atitudes como desmatar árvores. Outro desastre são as enchentes que também poderiam ser amenizados se jogássemos menos lixo nas ruas e cuidássemos mais em pesquisas sobre desastres e em modos de tentar contê-los para o número de perdas ser menor. A natureza precisa ser cuidada e nós somos responsáveis pelo bem dela (Fábio, 14 anos, Colégio Estadual Rocha Pombo).

Apesar de ainda estar preso à ideia do lixo e do desmatamento como causas principais dos desastres, o estudante percebe a necessidade de pesquisar mais sobre desastres dando abertura para a problematização do tema e outros encaminhamentos metodológicos para se chegar ao conhecimento científico, ao saber elaborado, a uma visão mais crítica da questão. Na categoria "Sobre o documentário" alguns estudantes resgataram as falas apresentadas nas entrevistas, como é o caso de Gabriel (13 anos, Colégio Estadual Maria Arminda), entre outros, que ao dizer que "a natureza é um dragão que não podemos enfrentar", cita a fala de Leonardo Boff que diz que "a Terra pode viver sem nós, mas nós não podemos viver sem a Terra".

Alguns alunos tentaram explicar o fenômeno baseado nas explicações apresentadas no vídeo, muitos reafirmaram a ideia do lixo jogado nas ruas ou nos rios como causa das enchentes e criticaram novamente as pessoas que constroem suas casas em áreas de risco, responsabilizando-as por saberem das consequências, outros entretanto alegaram vingança da natureza. Outros demonstraram mudanças de concepção ao perceberem que não é apenas um fenômeno natural; que as pessoas constroem suas casas em área de risco por necessidade e não apenas opção; que a prevenção de desastres é uma questão de gestão política; que não é um evento aleatório, mas uma conjunção de fatores; apareceram os avanços tecnológicos e o aumento populacional; o mau uso dos recursos públicos pelos governantes; e os efeitos das mudanças climáticas. Destaca-se que a atividade apresentou uma limitação de tempo para sua realização (quatro horas/aula, cerca de $200 \mathrm{~min}$ ), porém o professor poderia se estender no decorrer do ano letivo com a possibilidade de aprofundamento e exploração das questões suscitadas, em particular para divulgar as informações à comunidade no entorno.

De forma geral não há muita visão holística nas concepções dos estudantes, pois referem-se ao meio 
ambiente ou a natureza como algo desvinculado de suas vidas. É preciso reconstruir o sentimento de pertencer à natureza e ao fluxo de vida do qual se participa, levando a explorar os estreitos vínculos existentes entre identidade, cultura e natureza. A Educação Ambiental deve ir além da "educação 'a respeito do, para o, no, pelo ou em prol do' meio ambiente" (Sauvé, 2005). A relação dos seres humanos com o meio ambiente é, de fato, o objeto da Educação Ambiental. Nesse sentido, a apresentação do documentário "Quem Acordou o Dragão?" suscitou questionamentos sobre a relação dos seres humanos com o meio ambiente e serviu ao propósito de sensibilizar e despertar o interesse, a motivação e a curiosidade para as questões ambientais, levando ao desejo de pesquisa para o aprofundamento e melhor compreensão do tema proposto (Moran, 1995). Sobretudo nas escolas onde os estudantes vivenciaram o fenômeno, o debate abrangeu maior número de estudantes, validando a ideia de Arroyo (2013) de que além de trazer mais riqueza para o estudo, a realidade vivenciada por educadores e educandos e por suas comunidades, também proporcionam maior envolvimento dos atores que a vivem.

No entanto, o presente estudo também levantou questionamentos sobre a forma como a Educação Ambiental vem sendo desenvolvida na Educação Básica. A disciplina de Ciências apareceu como a principal responsável pelas questões ambientais no relato dos alunos, quando estas deveriam perpassar todas as disciplinas. E ainda, ao se observar a percepção ambiental geral dos alunos, a questão do lixo aparece como principal interferência humana na natureza. Tem-se a impressão de que o trabalho realizado nas escolas envolvendo a Educação Ambiental prioriza a gestão do lixo ou este é eleito como principal fonte causadora de problemas ambientais. Ou seja, uma Educação Ambiental voltada para minimizar impactos ao meio ambiente, como se esta fosse desvinculada do homem e sem a preocupação com a transformação da relação dos seres humanos com a natureza. Entende-se que a Educação Ambiental precisa ser revista em sua prática, visando à superação de uma visão ingênua e meramente reprodutora do sistema atual vigente. É preciso transformar a própria Educação para que se alcance a formação da cidadania crítica, a emancipação dos sujeitos e transformação do meio em que se vive. Instituir, portanto, uma Educação Ambiental emancipatória ou transformadora "em que a dialética entre forma e conteúdo se realiza de tal maneira que as alterações da atividade humana, vinculadas ao fazer educativo, impliquem mudanças individuais e coletivas, locais e globais, estruturais e conjunturais, econômicas e culturais (Loureiro, 2009). A própria formação de professores precisa ser repensada, uma vez que suas concepções interferem no processo educativo.

\section{CoNCLUSÕES}

Um dos propósitos deste estudo foi apresentar a Educação Ambiental como uma das estratégias de enfrentamento da crise ambiental e uma das formas de se alcançar uma prática social sustentável, focando a formação da cidadania crítica como instrumento de transformação das relações entre sociedades humanas e natureza. A utilização de vídeo de caráter regional nas práticas pedagógicas como recurso didático é sugerida como instrumento de sensibilização sobre a problemática ambiental no entorno, para que possa instigar o educando a questionar sua realidade, despertando o interesse pela pesquisa e a busca de soluções de problemas.

A pesquisa de campo realizada demonstrou a efetividade da utilização do vídeo como instrumento de contextualização de problemáticas que se deseja compreender, estudar ou resolver. Em particular o aumento das frequências após o uso do vídeo na categoria de análise "Argumentos científicos e/ou da realidade" trás, a partir dos materiais produzidos (textos e falas), a força da argumentação científica ou da realidade - o crescimento das 
frequências foi de no mínimo 25\% (escola Leôncio Correa) contrastando com menores crescimentos, ou até decrescimentos, em outras categorias de análise. Essa dupla argumentação "científica" e "baseada na realidade" pareceu dar mais força à construção das ideias dos estudantes, servindo por um lado a argumentação científica como a justificativa social mais legítima para explicar um problema e a força da garantia do real para a construção de princípios ou regras do mundo real. Assim, os argumentos são justificados cientificamente e corroborados pela realidade. Pareceu-nos também que sua utilização foi eficaz como ponto de partida para a realização de pesquisas sobre os problemas socioambientais no entorno, visando a instrumentalização para uma ação política e emancipatória dos educandos. O documentário “Quem Acordou o Dragão?” suscitou a reflexão sobre a questão ambiental e a relação ser humano e natureza, levando os estudantes a se perceberem como atores e/ ou sujeitos responsáveis pelo meio em que vive. O vídeo, por seu caráter regional, trouxe novos elementos para se pensar o entorno e despertou outros questionamentos para além da questão do lixo. O impacto foi geral, a metáfora do dragão desperto pelas ações humanas produziu o efeito desejado de chocar e despertar a consciência sobre os fatos ocorridos, porém a reação dos estudantes que vivenciaram o fato foi maior. Das três escolas localizadas nos municípios diretamente afetados pelas chuvas em 2011, duas citaram o desastre antes mesmo da apresentação do documentário. O tema das atividades e as imagens das charges os levaram a associálos aos fatos vividos em 2011, evidenciando que era significativo. As discussões após assistir ao documentário foram focadas na experiência vivida e evolveu maior número de alunos. A partir disso se observa que o vídeo é uma ferramenta educacional importante que deu conta de ampliar a análise da Educação Ambiental a partir dos desastres e que foi mais efetivo nas escolas que vivenciaram aquele processo. Dessa maneira, pode se sugerir que materiais didáticos de divulgação científica com caráter regional apresentam uma efetividade educacional e uma apropriação dos argumentos científicos maior quando aplicado ao público alvo que vivenciou o processo.

\section{REFERÊNCIAS}

Angelo C. 2015. Aquecimento extremo trará mortes em massa. Observatório do Clima, 29/09/2015. Disponível em: <http://www.observatoriodoclima.eco.br/aquecimento-extremo-trara-mortes-em-massa/>. Acesso em: 30/09/2015.

Arroyo MG. 2013. Currículo, Território em Disputa. 5.ed. - Petrópolis/RJ, Vozes.

Assman H. 1998. Reencantar a Educação: rumo à sociedade aprendente. $4^{a}$ edição. Petrópolis $\backslash$ RJ: Editora Vozes.

Atlas Brasileiro de Desastres Naturais 1991 a 2010: volume Brasil/Centro Universitário de Estudos e Pesquisa sobre Desastres. 2012. Florianópolis: CEPED UFSC.

Brasil. Lei no 9.795, de 27 de abril de 1999. Diário Oficial da União, Brasília, DF, Seção 1, 28/04/1999, p. 1.

Carvalho DW e Damacena FDL A. 2012. Intensificação dos Desastres Naturais, as Mudanças Climáticas e o Papel do Direito Ambiental. Revista de Informação Legislativa. Brasília a. 49 n. 193.

Demo P. 2011. Educar pela Pesquisa. Campinas/SP: Autores Associados. 
Furtado C O. 1974. Mito do Desenvolvimento Econômico. Rio de Janeiro: Paz e Terra.

Jacobi P. 2003. Educação Ambiental, Cidadania e Sustentabilidade. Cadernos de Pesquisa, nº 118, p. 189-205.

Labmóvel. 2012. Quem Acordou o Dragão? Direção de Antônio Luís Serbena. Matinhos: Laboratório Móvel de Educação Científica da UFPR Litoral. 1 DVD (53 min), color.

Leff E. 2010. Pensar a Complexidade Ambiental. In: . Leff, E. (coord.). A Complexidade Ambiental 2. Ed. - São Paulo: Cortez.

Lima SAK e Maluf RS. 2011. A incorporação das mudanças climáticas pelas políticas públicas. In: Maluf, RS e Rosa, TS (Coord.). Projeto Mudanças climáticas, desigualdades sociais e populações vulneráveis no Brasil: construindo capacidades - subprojeto populações. Volume I. Relatório Final de Pesquisa. Rio de Janeiro.

Loureiro CFB. 2005. Educação Ambiental e Movimentos Sociais na Construção da Cidadania Ecológica e Planetária. In: Loureiro, CFB, Layrargues, PP, Castro, RS. (Org.). Educação Ambiental: Repensando o Espaço da Cidadania. 3 ed. São Paulo: Cortez.

Loureiro CFB. 2009. Trajetória e Fundamentos da Educação Ambiental. 3 ed. São Paulo: Cortez.

Moraes R e Galiazzi MC. 2006. Análise Textual Discursiva: Processo Reconstrutivo de Múltiplas Faces. Ciência e Educação, v. 12, no 1, p. 117-128.

Moran JM. 1995. O Vídeo na Sala de Aula. Revista Comunicação \& Educação. São Paulo, ECA-Ed. Moderna [2]: 27-35.

Nobre CA. 2012. Fundamentos científicos das mudanças climáticas. Carlos A. Nobre, Julia Reid, Ana Paula Soares Veiga. São José dos Campos, SP: Rede Clima/INPE, 44p.

Sauvé L. 2005. Educação Ambiental: Possibilidades e Limitações. Educação e Pesquisa, São Paulo, v. 31, n. 2, p. 317-322. 